\title{
It just feels right: an account of expert intuition
}

\author{
Ellen Fridland ${ }^{1}\left(\mathrm{D} \cdot\right.$ Matt Stichter $^{2}$
}

Received: 26 December 2019 / Accepted: 13 July 2020 / Published online: 23 July 2020

(c) The Author(s) 2020

\begin{abstract}
One of the hallmarks of virtue is reliably acting well. Such reliable success presupposes that an agent (1) is able to recognize the morally salient features of a situation, and the appropriate response to those features and (2) is motivated to act on this knowledge without internal conflict. Furthermore, it is often claimed that the virtuous person can do this (3) in a spontaneous or intuitive manner. While these claims represent an ideal of what it is to have a virtue, it is less clear how to make good on them. That is, how is it actually possible to spontaneously and reliably act well? In this paper, we will lay out a framework for understanding how it is that one could reliably act well in an intuitive manner. We will do this by developing the concept of an action schema, which draws on the philosophical and psychological literature on skill acquisition and self-regulation. In short, we will give an account of how self-regulation, grounded in skillful structures, can allow for the accurate intuitions and flexible expertise required for virtue. While our primary goal in this paper is to provide a positive theory of how virtuous intuitions might be accounted for, we also take ourselves to be raising the bar for what counts as an explanation of reliable and intuitive action in general.
\end{abstract}

Keywords Skill · Expertise · Virtue · Intuition · Control · Action schema

\section{Introduction}

One of the hallmarks of virtue is reliably acting well. ${ }^{1}$ Such reliable success presupposes that an agent (1) is able to recognize the morally salient features of a situation,

${ }^{1}$ Zagzebski (1996, p. 137).

Ellen Fridland and Matt Stichter both contributed to this manuscript equally.

Ellen Fridland

Ellen.fridland@kcl.ac.uk

Matt Stichter

mstichter@wsu.edu

1 King's College London, WC2R 2LS London, Strand, UK

2 Washington State University, Johnson Tower 817, Pullman, WA, USA 
and the appropriate response to those features and (2) is motivated to act on this knowledge without internal conflict. Furthermore, it is often claimed that the virtuous person can do this (3) in a spontaneous or intuitive manner. The virtuous person, it is claimed, is the one who correctly 'sees' the morally salient features of a situation and which actions the situation calls for. Often, perceptual metaphors are invoked to explain such moral sensitivity. ${ }^{2}$ However, the perceptual metaphors by themselves do not suffice to show that virtue necessarily works like perception, as both defenders and critics have noted. ${ }^{3}$ Moreover, in order to be reliable in acting well, the virtuous person has to be motivated to act on the relevant situational knowledge, and without much internal conflict in so doing (or else she would be merely 'continent'). ${ }^{4}$ That is, for the virtuous person, the right action should emerge immediately and intuitively. As such, reliably accurate intuitions play a central role in explaining how the virtuous person is able to reliably act well, and to reliably act well in a spontaneous fashion. ${ }^{5}$

While these claims represent an ideal of what it is to have a virtue, it is less clear how to make good on them. That is, how is it actually possible to spontaneously and reliably act well? The worry is that such claims are assumed without understanding how, or even if, they are plausible. In this paper, we will lay out a framework for understanding how it is that one could reliably act well in an intuitive manner. We will do this by developing the concept of an action schema, which draws on the philosophical and psychological literature on skill acquisition and self-regulation. In short, we will give an account of how self-regulation, grounded in skillful structures, can allow for the accurate intuitions and flexible expertise required for virtue. We call this the "model-model" account of expert intuition. While our primary goal in this paper is to provide a positive theory of how virtuous intuitions might be accounted for, we also take ourselves to be raising the bar for what counts as an explanation of reliable and intuitive action in general.

Lastly, grounding our approach in the 'virtue as skill' thesis helps us to gain insight into virtue by reflecting on what we know about the acquisition and exercise of skills. ${ }^{6}$ On Matt Stichter's (2018) account, since skill acquisition is essentially a sophisticated form of self-regulation, by grounding an account of skill within the larger framework of the psychological research on self-regulation, we can shed further light on the nature of

\footnotetext{
2 McDowell describes this in terms that "one knows what to do, if one does, not by applying universal principles but by being a certain kind of person: one who sees situations in a certain distinctive way", and that this "sensitivity is, we might say, a sort of perceptual capacity". McDowell (1998a, p. 73 and 51) respectively. Hursthouse refers to this perceptual capacity as "situational appreciation - the capacity to recognise, in any particular situation, those features of it that are morally salient." Hursthouse (2016).

3 McDowell (1998b p. 162). Jacobson (2005, p. 388).

4 Aristotle, Nicomachean Ethics, 1107 a17-22. Zagzebski (1996, p. 108). Annas (2008, p. 30). See also Annas (2011, chapter 5).

5 In regards to moral intuition, Bloomfield points out that "The sense of 'intuition' here is quite different from the a priori intuitions posited by moral intuitions like Sidgwick, Moore, Ross, and Prichard. The relevant intuitions for virtue epistemology and moral epistemology are a posteriori”. Bloomfield (2000, p. 39). Lapsley and Hill make a similar point, though in comparison with the "front-loaded" automaticity found in the social-intuitionst model in psychology, when they claim that the expertise model that "locates automaticity on the backend of development. It is the outcome of repeated experience, of instruction, intentional coaching and socialisation." Lapsley and Hill (2008, pp. 324-325).

6 For example, see Annas (2011). Sosa (2007). Stichter (2017).
} 
skill and thereby virtue. Self-regulation theories cover both the considerations involved with setting goals and striving to accomplish those goals. ${ }^{7}$ In this paper we will briefly outline the main features of self-regulation, and then explore some of the implications of the research on self-regulation for skill acquisition and the 'virtue as skill' thesis.

\section{Self-regulation}

Self-regulation theories in psychology explain the mechanisms that allow us to pursue and achieve goals, where a goal is understood broadly as a desired or valued state of affairs_including enduring goals such as being honest or kind. ${ }^{8}$ Couching skill in this framework provides us with a general background theory on which skills can be seen as one species or kind of way in which goals are pursued and attained. Some essential components of self-regulation are detailed by control theory, or cybernetics, which explains the central processes involved with any goal-oriented system, including in virtuous agents, machines, and in animals (as goals can be the result of programming or instinct, as well as choice). As Stichter (2018) notes:

The basic stages to any form of regulation involve having: (1) a goal (or desired state of affairs); (2) a representation of the current state affairs; (3) a way to compare (1) and (2) to see if the goal is currently being met; and (4) if the goal is not being met, an action available within the system that can change the current state of affairs to meet the goal (and the system must then go through stages [2] and [3] again in order to know when the goal has been achieved). (p. 10)

However, those are just the minimal elements of a goal-directed system, and so that approach by itself doesn't address important complexities of self-regulation in humans, such as: (1) how people set new goals for themselves ${ }^{9}$; (2) how goals affect motivation for goal striving; (3) how feedback shapes our commitments to existing goals, etc. ${ }^{10}$ As noted above, a goal is a desired state of affairs, and one dimension of goals are their desirability. People have multiple goals, and those goals vary in their desirability, which in turn affects the motivation people have to strive for each

\footnotetext{
${ }^{7}$ Self-regulation is thus much broader in scope than what is more narrowly thought of as 'self-control', which is merely one aspect of self-regulation.

8 This also implies that there's an intention to strive to achieve the goal, given the context of self-regulation. For example, one might desire world peace as a state of affairs, but not have an intention to put effort into bringing that goal about.

${ }^{9}$ In control theory, the focus is on 'discrepancy reduction', in the sense that the system takes action only to reduce discrepancies between the goal state and the existing state of affairs. For people, we also significantly engage in 'discrepancy production', in that when we give ourselves new goals we are creating new discrepancies, which we then work to 'reduce'. See Bandura (1989, p. 37).

${ }^{10}$ In control theory, feedback mechanisms serve to notify the system whether to continue taking action to reach the goal state, or whether the goal state has been reached and no further action is required. It basically signals whether more goal striving is needed or not. But for people, the feedback we receive can also impact our goal commitments. For example, in the light of feedback that we haven't reached our goal, we might abandon that goal instead. Or if we achieved our goal and it had better outcomes than we originally anticipated, we might attach more value to that goal, which would then increase our motivation to strive for it. This is not an exhaustive list of differences, but we only have space to mention some factors briefly here.
} 
of them. ${ }^{11}$ This also has an affective dimension, as Albert Bandura relates, because "self-regulatory control is achieved by creating incentives for one's own actions and by anticipative affective reactions to one's own behavior depending on how it measures up to personal standards." 12 Such personal standards would include one's own moral standards, and the upholding of moral standards is a goal that one (ideally) is striving to uphold throughout one's life (and so need not be regarded as a one-off 'bucket list' type of goal). ${ }^{13}$ In regards to virtues, wanting to be honest, for example, is a personal standard that would provide motivation to both behave honestly and to make attempts to improve one's honesty. Insofar as one strives to be honest, then one will likely feel a guilty conscience when having done something dishonest (or even when contemplating doing something one knows to be dishonest). In terms of self-reactions, both making progress towards a goal and achieving it can be sources of self-satisfaction, while failing in opportunities to promote one's goal can lead to feelings of self-censure. Furthermore, the strength of the self-reaction, in terms of the motivation it provides for self-regulation, depends in part on how highly the goal is valued. ${ }^{14}$ This would then be an important factor for getting people to not only adopt virtues as personal goals, but also to view such goals as highly desirable to maintain.

The desirability of a goal, however, is not the sole factor to affect motivation. The adoption of a goal, and the motivation to pursue it when opportunities arise, also depends on whether the person believes they are capable of advancing or achieving their goal. For example, it might be very desirable to become an Olympic athlete, but given how difficult that is to achieve, it isn't feasible for most people to pursue it (especially at the cost of pursuing other desirable and more feasible goals). Thus, goal setting is both a matter of desirability and feasibility.

It's also important to note that many of our goals are highly complex or fairly abstract, i.e., superordinate (for instance, "become a grandmaster in chess"), such that it will be difficult to strive for them without having more context-specific, subordinate subsidiary goals to aim at (for instance, "work on my opening moves"), and this gives rise to a hierarchical organization of these connected goals. ${ }^{15}$ This could happen because the goal is complex and requires many intermediary steps to accomplish (as is common when trying to master a skill, for example), or because the goal is abstract and

\footnotetext{
11 One of the ways this motivation matters pertains to how we resolve conflicts that arise from having multiple goals (for example, due to having limited time and resources, or situations that afford opportunities to pursue mutually exclusive goals).

12 Bandura (1990). This does not mean, however, that such anticipation is necessarily conscious to the agent.

13 We should note that we are not assuming a particular metaphysical position on the nature of moral standards. Insofar as one adopts personal moral standards, that will provide some degree of motivation to self-regulate according to those standards, and that is what we are concerned with here.

14 That is, goals that are highly valued can provide more self-satisfaction from achievement, and likewise more self-censure from failing to achieve them, than goals that are only minimally valued. So motivation to strive for the goal arises from self-evaluative reactions (anticipated feelings of self-satisfaction or selfcensure), the strength of which depends in part on the degree of value placed on the goal.

15 This is different from a consideration of how valued the goal is relative to goals on different goal hierarchies.
} 
thus requires a more concrete specification to act on. ${ }^{16}$ Furthermore, the relationship between these different levels on a goal hierarchy need not be merely one of means to an end, as sometimes the lower order goals provide the constitutive elements of a higher order goal.

Once you have committed yourself to realizing a goal, it is time to start figuring out how you are going to realize it, and this marks a transition from goal setting to goal striving. ${ }^{17}$ As Stichter (2018) points out:

The reason for this distinction is that deciding whether to commit to a goal in the first place, or later whether to maintain commitment to that goal, requires a different kind of mindset from the activities associated with striving to achieve a goal (planning and acting). In short, in phases of motivation you are undecided about your goal commitments, whereas phases of volition assume a decided goal commitment that you are now trying to realize. (p. 15)

This distinction in self-regulation is also highlighted by Bandura, who notes that "people motivate themselves and guide their actions anticipatorily through the exercise of forethought. They anticipate likely outcomes of prospective actions, they set goals for themselves, and they plan courses of action designed to realize valued futures". ${ }^{18}$ Committing yourself to a goal is part of this process of forethought. It motivates the next phase of forethought in planning what steps to take to achieve that goal, where you are likely trying to figure out what needs to be done, how you are going to do it, when and where you will take action, etc. ${ }^{19}$ This will be the starting point for the development of action schemas, in order to achieve the goal, as we will further detail below. As such, acquiring or developing skill, expertise or virtue in a domain, requires shifting from goal setting mode to goal striving.

\section{Skill acquisition and deliberate practice}

On our view, skill acquisition is essentially a sophisticated form of self-regulation in which we engage in order to achieve a desired goal. That is, we develop skills in order to acquire the control and flexibility necessary to execute a wide variety of actions

\footnotetext{
16 In this sense, you want to be looking at subgoals that are more concrete for feedback, rather than trying to see how the act you're about to take contributes to the most abstract level on the goal hierarchy. For example, a player in a game who is trying to decide what move to make next is probably not going to be well served by thinking in terms of which move right now will most contribute to them eventually getting inducted into the hall of fame.

17 Switching from the setting of a specific goal into striving to achieve it, takes us from the vertical hierarchy of goal organization into a horizontal (or temporal) perspective on action, which is represented by the Rubicon model of action phases. Action phase theory separates goal setting and striving into four distinct phases: (1) choosing a goal to commit to; (2) planning how to achieve the goal; (3) taking action to implement the plan; and (4) evaluating one's progress with respect to the goal (and, if need-be, the appropriateness of the goal itself) in light of incoming feedback. Phases 1 and 4 are concerned with goal setting (or 'motivation'), whereas phases 2 and 3 are concerned with goal striving (or 'volition'). See Achtziger and Gollwitzer (2007, and Heckhausen (2007).

18 Bandura (1989, p. 19).

19 A similar claim is central to Bratman 's (1999) theory of intention, where settling on an intention prompts further practical reasoning for figuring out the means required for achieving that intention.
} 
aimed at achieving specific outcomes in fast, accurate and efficient ways. In this way, through skill learning, we calibrate our goal striving to effectively meet our set goals. That is, through skill learning we enhance the control and flexibility that we have over the ways in which our ends can be met.

The claim that we will forward in this section is that skill acquisition is the result of a continued kind of practice, namely, deliberate practice (Ericsson et al. 1993; Montero 2016; Fridland 2019; Stichter 2018). It is through deliberate practice that we develop the control to flexibly regulate our behaviors in order to efficiently reach our desired ends. We emphasize continued deliberate practice in order to ensure that skills, and thus the structures that ground virtue, exhibit both control and flexibility. That is, we insist that skills are the sorts of things that we can easily manipulate and adjust appropriately in ways that are firmly connected to our goals. This aspect of skill is crucial for retaining and understanding the intelligence of skill in general and of virtue in particular. We will contrast the result of learning through practice with learning through mere repetition, a kind of learning that does not necessarily yield sustained improvements, control, or flexibility. This will help us to see why deliberate practice is necessary for skill but it will also help us to see why it is that the products of deliberate practice can provide us with reliable, intelligent intuitions rather than rigid, rote, inflexible or systematically erroneous ones.

The first thing to notice is that practice is a kind of repeated action or activity that characteristically yields improvement or learning as a result. ${ }^{20}$ To note, practice isn't just repeated behavior that result in more efficient movement quality but a repeated behavior that is done intentionally-practice, in this way, is a kind of action. In other words, skill improvement is itself a goal, and practice is a subgoal. Additionally, deliberate practice requires not only performing some action repeatedly and intentionally but performing it with a specific intention to improve. That is, deliberate practice requires having specific targets for improvement, rather than just a vague goal of 'getting better'. There need to be specific aspects of your performance that you plan how to improve, which then structure the deliberate practice in which you engage. ${ }^{21}$ Often, the subgoals, instrumental strategies or techniques that lead to an end themselves become the targets of practice. That is, in deliberate practice we aim to improve not only the overall success of an action but also the means by which we achieve that success (Fridland and Moore 2015; Fridland 2013a, b). Crucially, as Stichter (2018) draws attention to:

As you engage in deliberate practice you seek out feedback about your performance, in the hopes of identifying and correcting errors. You keep monitoring your progress as you practice. If you do not seem to be progressing, you may need to redesign your practice sessions. If instead you keep up a steady progression, then at some point you achieve your current goal. At that point it is time to set out to strive to accomplish the next more difficult goal (i.e. you advance to planning how to achieve the next higher-ordered subgoal on the vertical hierarchy). This is how you improve upon your current level of performance. (p. 25)

\footnotetext{
${ }^{20}$ Lots of people agree that skills are learned through practice:. e.g. Stanley and Krakauer (2013), Fridland (2014), Montero (2016), etc.

${ }^{21}$ Horn and Masunaga (2006, p. 601).
} 
Importantly, empirical research in psychology supports the claim that repeated deliberate practice aimed at improvement is necessary for producing the benefits in performance that we take to be characteristic of skill. It turns out, in fact, that the quality of the practice matters just as much as quantity. That is, sheer repetition is not sufficient for sustained improvement and skill development (Ericsson et al. 1993; Duke et al. 2009). In fact, according to this line of research, improving your level of skill requires not the mere repetition of things you already know how to do, but continually striving to do things that you currently cannot do. This means that the acquisition of skill and virtue is something that an agent does and is responsible for doing.

Critically, the sustained improvements that result from deliberate practice are possible because through this method of learning we acquire abilities that are both controlled and flexible. That is, deliberate practice allows us to develop abilities that we can manipulate, adjust and adapt in various appropriate ways that are firmly connected to our goals. In short, to ensure goal satisfaction in different contexts and circumstances - often novel and dynamic — that is, to ensure control, we need skills that are flexible and that can be intervened upon and adjusted to various degrees, in different ways as required. In short, we need skills that are flexible in order to have actions that are controlled. And it is continued deliberate practice that allows for this.

To reiterate the point, repetition alone, even if it leads to reliable success that is procedurally automatic is not sufficient for skill. Crucially, this is because repetition can lead either to rigid, canalized, inflexible behaviors (like habits) or controlled flexible ones (like skills) and which it leads to depends on how the ability is acquired and repeated (Sutton et al. 2011, Ericsson et al. 1993). As Ryle (1949) asserted so long ago, the difference between habit and skill is that in skill we are constantly learning:

[A] mountaineer walking over ice-covered rocks in a high wind in the dark does not move his limbs by blind habit; he thinks what he is doing, he is ready for emergencies, he economises in effort, he makes tests and experiments; in short he walks with some degree of skill and judgment. If he makes a mistake, he is inclined not to repeat it, and if he finds a new trick effective he is inclined to continue to use it and to improve on it. He is concomitantly walking and teaching himself how to walk in conditions of this sort. It is of the essence of merely habitual practices that one performance is a replica of its predecessors. It is of the essence of intelligent practices that one performance is modified by its predecessors. The agent is still learning. (p. 42)

In short, skills are distinct from many behaviors in their vicinity like habits or repeated stereotypical actions because skills result from deliberate practice which yields sustained improvements that are flexible in execution, and controlled in their systematic integration with an agent's goal states or intentions. This makes these sorts of actions intelligent and it also makes this model an appropriate one with which to think of virtue. Our claim is that the flexible and controlled actions that result from deliberate practice are different in critical ways from the products of other kinds of repetitive or rote behaviors. In the next section, we will see that the manipulability and flexibility of skills ensures that the intuitions that emerge through skill acquisition are reliable, appropriate, and effective guides for action. This is precisely because 
skills have an ongoing openness, sensitivity, and responsiveness to the world and the agent - continually revising and refining in order to become more attuned to the relevant qualities of the environment and the actor. That is, skills remain open to improvement while other repeated behaviors can become stilted, formulaic, and closed. It is this latter stultification that poses a danger to our intuitions - all but ensuring their lack of sensitivity to novelty and change-making them outdated and ineffective. In contrast, in constantly seeking to improve, we intentionally keep open and flexible the structures that make skill possible, allowing for a more accurate and appropriate response to our circumstances and, thus, a more reliable intuition as a result. This is also why such a model makes the virtue as skill hypothesis so plausible.

\section{Knowledge, action, schemas and models}

To say that deliberate practice develops and sustains the control and flexibility of skill is not yet to say fully what it is that we learn when we learn a skill. To be clear, of course, on the one hand, we have indeed said what we learn: flexibility and control. But on the other, we haven't yet introduced the cognitive structures that make such flexibility and control possible. In this section, this is precisely what we aim to do: we will provide a sketch of the cognitive states that are produced as a result of deliberate practice and which manifest in the flexibility and control that is characteristic of skilled actions. That is, we seek to provide an account of the cognitive control structures that make control in action, at the manifest level, possible.

To begin, we should notice that one thing that changes as we develop our expertise in a particular domain is our knowledge of that domain. Importantly, however, there are different positions regarding precisely how we ought to think of the knowledge that guides skilled action. ${ }^{22}$ At this stage in the paper, we will be concerned not so much with the nature of knowledge itself but with the organization of knowledge. We will begin with knowledge structures as they are often discussed in psychology. The term 'schema' refers to the way in which we organize knowledge, including how such knowledge is stored and later retrieved. ${ }^{23}$ Since we are constantly presented with an overwhelming amount of information regarding ourselves and our environment, we need a way to efficiently organize this information, and we do this by forming schemas. As Stichter (2018) explains:

Schemas organize our information into different categories and help us to interpret the world around us. A simple example is having a schema for a cat something that is furry, has four legs, a tail, whiskers, makes purring sounds, etc. This schema can include both these generic details, as well as more specific information like the features and personalities of the cats you have kept as pets. There will be a lot of overlap between people with the generic details in a simple schema like 'cat', though of course there will be a lot more variation when it comes to calling to mind particular cats you have encountered. This schema makes it easy to identify other cats in your future encounters, as the animal in

\footnotetext{
22 See, for instance, Fantl (2017) for an overview of the debates concerning knowledge how.

23 Cantor (1990).
} 
front of you will be compared to your existing schema and will be recognized as a cat if it fits the schema. This also has the effect of making it easy to encode this new information into your memory. However, new experiences can also lead you to revise your present schema, for example when you encounter a cat with only three legs. (pp. 36-37)

Furthermore, schemas do not operate in a purely passive way since the way in which we categorize information has robust follow on effects on our thoughts and actions.

Like with object categorization, we can expect there to be variation in the ways in which people will categorize and understand events. This is the case because people vary in their schemas (as well as their motivations and perspectives) as a result of their different experiences and how those experiences are interpreted in light of preexisting schemas. This is particularly relevant when it comes to skill because it helps us to see why the different schemas of experts and novices result in information that may be noticed, categorized, and interpreted differently. A novice in chess, for instance, will start out with a fairly vague schema of the domain - it involves two players, a board with some pieces with different shapes and values, and some very basic knowledge of how those pieces move, etc. An expert, by contrast, has developed a number of complex schemas that represent not only the board and the value of the pieces but countless patterns and values of various chessboard configurations. ${ }^{24}$

A final important aspect of schemas worth noting is that the more a schema is used, the easier it is to call it to mind again. In short, schemas can vary in their accessibility and a schema that is frequently called to mind is said to be 'chronically accessible'. This is then another way in which people can vary with respect to schemas-in terms of how accessible the schema becomes. Schemas develop and improve as one learns a skill and this will in turn change not only how knowledge about the skill domain is organized but also how easily one can apply the appropriate schema to the relevant situation.

We should note, however, that as described above, schemas explain how we identify, categorize, understand and interpret events or objects but they do not tell us how knowledge of a specific domain is related to guiding action. That is, schemas tell us why certain people acquire the beliefs they do about certain situations but they don't tell us why they respond to situations in the ways they do. In cognitive science terms, schemas tell us about how we organize inputs but they have little to say about the organization of output. But we know, after all, that experience not only changes how experts view a situation, it also enables them to efficiently and effectively respond to that situation. Of course, we can refer to experience of successful past decisions and appeal to pattern matching in order to explain how it is that experts are able to automatically select a response to a complex situation. But, as we shall see, this approach will not be sufficient to explain skill.

So, for instance, we can appeal to the highly developed schemas of experts and see why it is that possession of a schema makes it easier for an expert to react appropriately to similar situations in the future. The idea is basically that a complex schema allows an expert to recognize that she has been in this situation before, and if she has acted

\footnotetext{
$\overline{24}$ See Chase and Simon (1973a, b), for example, for evidence that experts develop ways of organizing and accessing patterns of perceptual information specific to their domain of expertise.
} 
successfully in past, then she can respond now with the same response as in the past, without the need to stop and deliberate about what to do next. Essentially, she is pattern matching between a current situation and past situations the knowledge of which has been organized into schemas.

As helpful as pattern recognition can be, however, it does not suffice to explain the decision-making capabilities of those with a high degree of skillfulness. Pattern matching gives us something, of course, but it does not give us flexibility and control-which as we saw above, are essential to skill and most certainly to virtue as well. That is, pattern matching can only tell us that when a situation that is encountered is sufficiently similar to one that has been experienced in the past, then it will likely trigger the reinforced response that is associated with the previously learned situation. Or, it will tell us that when a goal in a particular context is the same as the goal in past situations, then the same previously successful actions will be initiated again. However, as the description should make clear, what we have here is not a flexibly controlled action but a habit-like response that is triggered by a previously learned schema. ${ }^{25}$ That is, we don't get variation in goals in similar situations nor do we get variation in action plans when goals are the same. In order to account for flexibility and control, it seems, we must do more. That is, we need more than mere look up tables but information that provides us with a deeper understanding of the skill domain.

It is here that mental models come in. Mental models are defined as "mechanisms whereby humans are able to generate descriptions of system purpose and form, explanations of system functioning and observed system states, and predictions of future states". ${ }^{26}$ It is precisely because we gain a deeper understanding of the mechanisms of control and principles governing the model domain that models are effective in regulating our behavior in a given system. That is, models provide us with control because they not only provide us with instances of past experience but also with a fundamental understanding of how a system functions and why experiences are the way they are. This understanding thus allows us to make predictions about the future states of the system without necessarily basing those predictions merely on past experiences. Instead, those predictions can be based on our understanding of the function and principles governing how the system works. ${ }^{27}$ As such, models gives us more flexibility than pattern matching because modeling allows us to take into account the relevant features of a situation in order to more accurately predict potential outcomes even in novel situations. Still, we should note that mental models are a type of schema, and like schema they involve abstraction away from one's particular experiences. ${ }^{28}$ As Mica Endsley points out about mental models, "although they grow and evolve with experience, largely represent static knowledge about the system-its significant

\footnotetext{
25 See Sutton and Barto (1998), and, for instance, Cushman (2013) for more on reinforcement learning and how to understand model free v. model-based learning processes.

26 Rouse and Morris (1985).

27 In this respect, the role of past experience is more indirect than pattern matching suggests-experience updates our mental models, which are then used to make predictions (but predictions based on a synthesis of past experiences, rather than pattern matching to one particular experience).

28 "The useful utilization of events as familiar requires a degree of appropriate abstraction, both in the event features utilized and in the memory organization imposed on the memory models themselves." Feltovich and Ericsson (2006, p. 54)
} 
features, how it functions, how different components affect others, and how its components will behave when confronted with various factors and influences." ${ }^{29}$ In terms of experiences that shape mental models, deliberate practice plays a significant role in helping us flesh out our mental models of a domain, as mere rote repetition does not supply much in the way of new information to allow such models to grow in complexity.

Beyond the role of mere experience in shaping mental models, Seligman, Railton, Baumeister, and Sripada's work on prospection helps to explain why such models are effective. ${ }^{30}$ As mentioned earlier in regards to the use of forethought in goal setting and striving, prospection involves generating representations of future possibilities. It is a matter of having expectations of the form "if in circumstance $C$ and state $S$, then behavior $B$ has outcome $O$ with probability $p . " 31$ Such expectations can then guide future action, based on accurate predictions of which interventions will have which outcomes. In this regard, mental models are not so static as pattern matching, because you're modeling different potential outcomes, which allows for flexibility in behavior based on which outcome one is pursuing in the situation (and this can be a different outcome than one had in a previous encounter with a relevantly similar situation). Furthermore, the more accurate the expectations, the better one can be guided by prospection. So mental models provide knowledge about a system that involves generating accurate predictions, which can in turn inform action planning.

\section{Action schemas}

At this point, we would like to clarify our position concerning the cognitive structures that are learned through practice and which ground both skill and virtue-structures that we will call "action schemas". We would like to retain the basic concept of a mental model, with all of its deep understanding of a system's function and prospection, but emphasize that the cognitive structures relevant for developing and sustaining skilled actions are directly involved not only in representing a system but also in planning and guiding action within that system. That is, we are interested not only in how epistemic states allow for accurate prediction and understanding of a system but also how those states allow us to seamlessly and effectively navigate that system through appropriate, skillful action. We are, after all, interested in the practical knowledge that allows us to control behavior and not just theorize about it. It is for this reason that we think skills require practically organized action schemas.

To this end, we contend, following Myrto Mylopoulos and Elisabeth Pacherie (2017, 2018), who themselves follow Schmidt (1975, 2003), that the schemas or models that support skilled action are both informational and control mechanisms. That is, schemas are concerned not only with organizing knowledge about a system but in guiding the actions of agents within that system. As Mylopoulos and Pacherie explain:

\footnotetext{
29 Endsley (2006, p. 638).

30 Seligman et al. (2013).

31 Seligman et al. (2013, p. 124).
} 
According to schema theory, motor schemas are both repositories of information and control structures. They are internal models or stored representations that represent generic knowledge about a certain pattern of action and are implicated in the production and control of action.... The generalized motor program is thought to contain an abstract representation defining the general form or pattern of an action, that is the organization and structure common to a set of motor acts (e.g., invariant features pertaining to the order of events, their spatial configuration, their relative timing and the relative force with which they are produced" (M\&P 2017, p. 330).

Importantly, motor schemas not only organize knowledge about a domain of action through the structured representation of information about the action or skill but they are themselves involved in guiding the action or skill as it is planned and implemented. In this way, motor schemas are both epistemic and implementation structures. They are both knowledge and control states. Crucially, like mental models, motor schemas control by representing, not only, for instance, information about the shape and structure of an action, like sequence, timing, force, effector involvement, trajectory, etc. but also by encoding the predicted sensory outcomes that the motor programs should produce when generated. That is, like forward models, they make predictions about what should be the case, when the program is run.

So, from motor schemas, we would like to borrow the idea that the structures that sustain skilled actions do dual work: they both represent and guide skilled action. And from mental models, we would like to borrow the idea that knowledge structures are personal-level mechanisms that can provide us with a deep understanding of a system and its governing principles. The idea of prospection or predicted outcomes is central to both concepts. We have already seen the advantage of mental models. What we would like to emphasize here is the advantage of conceiving of action schemas not only as personal-level cognitive representations that undergird understanding of a domain but that can themselves be involved directly in the guidance, planning, and control of complex, skilled actions.

The first reason to prefer a practical theory of knowledge organization in the case of skill and virtue is because this kind of account helps us to explain why experience is required for building the schemas of experts. After all, we want to explain why it is that experts, who have extensive experience and hours and hours of deliberate practice in a domain, are better at recognizing, categorizing, interpreting and responding to situations than others who lack this type of experience. That is, we want to explain why a skilled baseball player or seasoned firefighter understands and responds to situations in ways that are unavailable to the novice or theoretician. We want to explain why the knowledge that the skilled agent has is a practical kind of knowledge and action schemas allow us to do this because on such an account, without control of the system we don't get knowledge of it and vice versa.

Secondly, and perhaps even more importantly, we also want to explain how organized knowledge structures are immediately and spontaneously connected to appropriate action selection and planning in a domain. That is, we want to explain not only how a well-developed schema can help us to predict what will happen in a given situation but how that schema can itself form and shape action plans and sub- 
goals. Importantly, a schema can do so directly, rather than as an input to a decision procedure. ${ }^{32}$ By seeing actions schemas as both epistemic and practical structures we have a way of explaining how prospection can serve both an epistemic and practical end. That is, we can explain how a predicted outcome can serve as a goal of action.

To see how this might be the case, we turn briefly to ideomotor theories of action. According to ideomotor theories of action, actions are represented in terms of goals or predicted sensory outcomes (See Hommel 2015, 2009; Prinz 1997; James et al. 1890). So, for example, reaching actions are specified, first and foremost, in terms of the predicted sensory end-state of the reach. Grasping actions are specified not simply in terms of the motor commands necessary for generating a grasping motion but by the goal of the grasp. The end-state is what guides the selection of the appropriate motor program or command. ${ }^{33}$ The action, in this way, is coded in terms of its goals. ${ }^{34}$

Connecting ideomotor theories of action to the idea of prospection, we can see that accurate predictions of future outcomes can be used as more than information for decision-making and deliberation but as a goal to organize appropriate actions around. In this way, a predicted end can itself function as an intention, which automatically and flexibly connects to an appropriate action plan. After all, the schema, through experience, has already connected various action plans to their outcomes. Furthermore, this experience has also made such schemas more highly accessible, thus making such intentions more likely to be carried out. ${ }^{35}$ This may provide for a self-reinforcing mechanism, as further goal striving increases the accessibility of a schema, and the greater accessibility facilitates acting on that goal intention when future opportunities arise, which leads to more goal striving, etc. ${ }^{36}$ This self-reinforcement mechanism could then play an important role in the development and exercise of the virtues, as

\footnotetext{
32 Otherwise the knowledge in a schema seems inert (i.e. background information) until one deliberately incorporates such knowledge in carrying out a separate action - implementing a decision procedure. It is this claim that we are rejecting.

33 This extends the relevance of the framework of goals in self-regulation beyond what is typically discussed in the psychology literature. Of course goal setting and goal striving are connected, but ideomotor theory is drawing a tighter connection insofar as actions are being represented in terms of the goal to be achieved. In this way, goals exert a more direct influence on the selection of actions.

34 See Hommel (1993) for evidence that what is pursued is a goal and not just sensory outcome.

35 Likewise, action schemas when not used can become less accessible over time. For example, while some level of skill may be kept even when not used frequently, as the cliché 'it's like riding a bike' expresses, the same is not true of higher levels of skill (such that it wouldn't be as easy to perform a difficult mountain biking trail if one hadn't been practicing). Or as another example, you may be able to still play some pieces on the piano after years of having done so, but you are unlikely to know how to play very complicated sections of a piece that you used to know. Evidence for this comes from research on aging and expertise, where it was discovered that deliberate practice is necessary to maintain a high degree of skill development. One's level of skill development requires some level of routine practice to maintain it or the level of skill degrades over time. See Krampe and Charness (2006).

36 This dynamic is also present in Sheldon and Elliot's work on the self-concordance of goal-systems, wherein concordance is "the degree to which stated goals express enduring interests and values." When goals are not concordant, this affects both goal striving (i.e reducing goal motivation and thus progress) and the outcomes of goal attainment (i.e. not as fulfilling). By contrast, there's a potentially self-reinforcing cycle in adopting more 'concordant' goals. Sheldon and Elliot explain that "Because the developing interests and deep-seated values that such goals express are relatively enduring facets of personality, self-concordant goals are likely to receive sustained effort over time." So self-concordant goals are more desirable, providing more sustained motivation, leading one to put more effort into striving for such goals, and this leads to higher rates of goal progress and attainment. Sheldon and Elliot (1999, p. 482 and pp. 483-484) respectively.
} 
adopting virtues as personal goals would then be linked up with action schemas in the same way, helping one to act on one's virtuous intentions. This also connects to motivation as it becomes easier to act on that intention (such that there is less friction, or contrary inclinations, in acting on virtuous ends). ${ }^{37}$

Also, recall, those connections are not simply learned through brute, associative, reinforcement but involve a deep understanding of the functional principles and form of the overall system. As such, with the development of action schemas we gain not only an understanding of a domain but a direct way in which that understanding, through outcome prediction, can guide skillful and flexible action selection, execution and control. In this way, we explain not only how we know about a domain but how we develop the facility to act spontaneously and intelligently in that domain.

In short, we claim that action schemas connect representations of complex actions to predicted outcomes of those actions. In doing this, action schemas guide our action planning and organize action implementation through prospection and a deep, practical understanding of the functional and formal principles that govern the action domain. As such, in developing action schemas we develop complex practical organizational structures that support both skilled knowledge and skilled control.

\section{Explaining expert intuition in virtue}

Importantly, we should notice that because action schemas both represent and guide actions, the possession of these sorts of cognitive structures facilitates appropriate, intuitive action selection in fast, immediate and spontaneous ways. That is, it is because action schemas encode both a structured, practical representation of the action or skill and of the predicted outcome of that action, an agent can attend to a particular action array (let's say a basketball game) and plan (immediately, intuitively) based on the situation of play on the court, what actions she needs to undertake in order achieve the intended result (making a basket/getting the ball from the other team, etc.). That is, possessing detailed and accurate action schemas that have been developed through deliberate practice accounts for why certain situations afford, immediately and spontaneously, certain appropriate and intelligent actions to some agents but not to others. It explains the intuitive ability to determine and perform the appropriate action now.

Action schemas do this, we contend, because cuing the outcome of an action can immediately bring to mind the related action plan required for the fulfillment of that goal. So, when a skilled agent looks to what she wants to achieve, the practical plan for how to achieve it comes spontaneously, immediately, automatically to mind. [Aiming for $o$, (automatically) selects $a$ for $S$, when $S$ has a (well-learned) action schema for $o$ ]. That is, the agent intuitively knows what to do, given her goals, because the goal

\footnotetext{
37 On this, Zagzebski claims that "Although some virtues involve being able to do difficult things, the difficulties involved are due to contrary inclinations (past or present)". Zagzebski (1996, p. 108). Annas has argued that this claim about a lack of contrary inclinations can be understood in terms of the psychological concept of 'flow', such that "virtuous activity, as opposed to merely self-controlled activity, is pleasant, not in involving extra feelings but in being unimpeded by contrary impulses, and in harmony with all of the person's thoughts and feelings.” Annas 2008, p. 30). See also Annas (2011, chapter 5).
} 
and the way of achieving it are connected to one another in a control structure, in an action schema. As such, the appropriate means for achieving the goal are tied immediately to the intending or selecting of the goal. And this entails that the skilled agent can immediately respond to the situation with the appropriate actions. Moreover, we should also notice that action schemas developed through deliberate practice not only connect the appropriate strategies to desired outcomes but also make those links easier to access, since schemas become more accessible the more they are used. As such, the intuitive plan of skilled action is both accurate and efficient.

We should notice, however, that it is not only the appropriate way of achieving an already fixed goal that becomes intuitive for the skilled agent but also the intuitive selection of appropriate goals and subgoals. This can happen when an action or set of actions is considered, likely through imaginative simulation, by running an action schema offline. ${ }^{38}$ In this way, the skilled agent can quickly make predictions about potential outcomes and immediately adopt the appropriate goal or subgoal for action. In this way, we see that the possession of an action schema allows us to account for both the reliable and accurate intuition of skilled agents in selecting their strategies for reaching a specified goal and also for deciding which goals or subgoals are most appropriate in a specific skill domain.

Again, however, it is worth noting that this tethering of action plan and goal that is created by the use of action schemas retains the flexibility and control that is characteristic of intelligent actions. This is because the connections between plans and outcomes are formed through deliberate practice, thus engendering an appreciation of the deep functional features of the system. This appreciation, we maintain, is inherent to construction and structure of the action schema. That is, action schemas are models that are built out of intelligent and flexible parts. Being thus formed allows for the manipulability, adaptability, and sensitivity of action schema to the particular situations and goals as they formulated in the current context, and not only as they have been in the past. The idea is that with expertise, one becomes sensitive in intelligent ways to the most relevant features of a system. This type of sensitivity then promotes not a simple triggering of associated behavior but the selection of appropriate action. And it does this directly, not by way of being an input into a separate discursive, deliberative process but by selecting and connecting means and ends in ways that express a deep understanding of the principles governing the system. That is, the intelligence of action schemas is not added by a separate process of conceptual reasoning from a predicted outcome to a preferred plan but, rather, the reasoning is done, likely by simulation, in the actual selection and shaping of the goal and action plan. That is, the plans themselves are formed in intelligent, flexible, and appropriately responsive ways.

This kind of flexible connection between situation, goals, and plans also lets us see why the reliable intuition of experts should be contrasted with the stilted and stereotypical judgment or action selection that come as a result of overlearned, rote, habit-like responses. That is, seeing that deliberate practice promotes the construction of subtle, fast, and accurate practical cognitive structures that are continually improving

\footnotetext{
38 See Kosslyn et al. (2006) and Jeannerod (1994) for more on the connection between imagination and perceptual-motor simulation.
} 
and thus retain both flexibility and control, provides us with good reason to hold that skilled agents develop reliable intuitive responses in their area of expertise.

We believe action schemas can also explain how someone with a well-developed virtue would have reliable intuitions about how to act morally (as well as being motivated to act on such intuitions). Since action schemas are connected to goals, a similar story would apply to someone who adopts and achieves a virtue goal. Someone who is honest, for example, would have a highly accessible action schema for honest behavior, which would shape their perception of situations such that they are sensitive to when a situation calls for honesty along with specific, well-honed plans for how to express that virtue appropriately in practice. Presumably, we have plenty of opportunities in real life to practice honest and dishonest behavior. Reactions from others as to whether our actions are in alignment with a commitment to genuine honesty, as well as personal standards of success, can serve as feedback for the development and calibration of virtuous action schemas. ${ }^{39}$ Such feedback can help us learn the difference between honesty and brutal frankness, for instance, or between telling people what they need to know versus being selective with the truth in a way that is deceptive. Often, we will have to learn virtue through real-life experiences, and growth will be incremental, but it's also well recognized that developing virtue is a lifelong practice.

As another example of virtuous intuition in practice, consider responding to a fairly common microaggression. Say that a group of philosophers are having dinner together after a talk and the most senior male philosopher (SMP) consistently asks the women at the table about their husband's work while asking the male philosophers about their philosophical positions. An action schema for handling sexist microacroggressions would involve noticing that a wrong is taking place and immediately responding by choosing a suitable course of action, e.g., making a subtle joke to make the inappropriateness clear but not making the victim feel uncomfortable and then changing the subject. Or, engaging directly with the victim to discuss her philosophical work. Or, interrupting the SMP by asking the victim about her work and engaging the SMP in that discussion. Importantly, which response is appropriate will depend on the context and how one can navigate the tricky situation best. The well-honed action schema, we contend, will enable the virtuous agent to spontaneously and flexibly select the appropriate response for that particular situation.

Importantly, action schemas for virtue, though often developed through real life experiences, can also be improved through deliberate practice. First off, real life can count as practice, if approached in the appropriate manner: as an opportunity for improvement. Also, if one is intent on developing or refining a particular virtue, one can seek out real life situations where that virtue may be acquired and improved. Still, we must grant, of course, that it is difficult to structure practice sessions for virtue. It's not as straightforward, after all, as someone practicing their golf swing or working on their free throw shots in basketball practice. ${ }^{40}$

Notwithstanding, we would like to draw the reader's attention to the possibility that deliberate practice via simulation can provide a foundation upon which we improve

\footnotetext{
39 Of course some people may only have adopted the non-moral goal of appearing honest, to say avoid punishment or to do good business.

40 Though see Stichter (2020) for examples of moral courage training programs that successfully use deliberate practice sessions.
} 
and refine our action schemas for virtue. After all, it is well documented that mental practice is an effective strategy for improving actual performance. ${ }^{41}$ And it is very likely that mental practice is effective precisely because it refines via imagination the very same mental mechanisms that are involved in performing the actual task. ${ }^{42}$ As such, carefully and deliberately visualizing or simulating various specific ethical scenarios in one's mind should help reinforce and refine the relevant action schemas for those situations. Moreover, we contend that not only is such mental practice a theoretical possibility for developing virtue but that we actually engage in this type of practice all the time. Think of the all-too-familiar experience of playing and re-playing a difficult moral or high-stakes situation over and over in one's mind in great detail. This can happen whether the situation is in the future or the past and often involves subtle variations and modifications to one's behavior and predictions of reactions or responses. This phenomenon, we suggest, gives us good reason to believe that the honing via simulation of action schemas for virtue is not only possible in principle but in fact occurs regularly via deliberate mental practice.

\section{Conclusion}

By thinking of skill and expertise as sophisticated forms of self-regulation, we are able to get a handle on intuition, generally, and on the ways in which reliably accurate intuition may develop in virtue, specifically. This gives us a way of explaining both the accuracy and immediacy of the virtuous person's perception and intuitive responsiveness to a situation and it also gives us further reason to prefer a virtue as skill account of virtue. Moreover, such an approach gives us the resources to explain with some rigor and precision, the ways in which expert intuition can be accounted for, by appeal to action schemas. Lastly, our approach provides reason to think that expert intuition in the realm of virtue can indeed develop over time and with practice in a way that is flexible, controlled and intelligent. It lends credence to the view that virtue is learned and that we can act reliably and well by grounding our actions in expert intuition.

Funding Funding was provided by the Templeton World Charity Foundation (Grand Number TWCF0262).

Open Access This article is licensed under a Creative Commons Attribution 4.0 International License, which permits use, sharing, adaptation, distribution and reproduction in any medium or format, as long as you give appropriate credit to the original author(s) and the source, provide a link to the Creative Commons licence, and indicate if changes were made. The images or other third party material in this article are included in the article's Creative Commons licence, unless indicated otherwise in a credit line to the material. If material is not included in the article's Creative Commons licence and your intended use is not permitted by statutory regulation or exceeds the permitted use, you will need to obtain permission directly from the copyright holder. To view a copy of this licence, visit http://creativecommons.org/licenses/by/4.0/.

\footnotetext{
41 See, for instance, Feltz and Landers (1983), Driskell et al. (1994), Guillot et al. (2009), Hanakawa et al. (2003, 2008), Madan and Singhal (2012), Schack et al. (2014).

42 Decety and Michel (1989), Decety et al. (1992), Jeannerod (1994), Cohen et al. (1996), Kosslyn (1999), Kosslyn et al. (2006), Schack (2004), Schack and Mechsner (2006), Schack et al. (2014).
} 


\section{References}

Achtziger, A., \& Gollwitzer, P. M. (2007). Motivation and volition in the course of action. In J. Heckhausen \& H. Heckhausen (Eds.), Motivation and action (pp. 202-226). New York: Cambridge University Press.

Annas, J. (2008). The phenomenology of virtue. Phenomenology and the Cognitive Sciences, 7, 21-34.

Annas, J. (2011). Intelligent virtue. Oxford: Oxford University Press.

Bandura, A. (1989). "Self-regulation of motivation and action through internal standards and goal systems. In Lawrence A. Pervin (Ed.), Goal concepts in personality and social psychology (pp. 19-85). London: Lawrence Erlbaum Associates.

Bandura, A. (1990). Social cognitive theory of personality. In Lawrence A. Pervin \& Oliver P. John (Eds.), Handbook of personality: Theory and research (pp. 154-196). New York: The Guilford Press.

Bloomfield, P. (2000). Virtue epistemology and the epistemology of virtue. Philosophy and Phenomenological Research, 60(1), 23-43.

Bratman, M. (1999). Faces of intention: Selected essays on intention and agency. Cambridge: Cambridge University Press.

Cantor, N. (1990). From thought to behavior: "Having" and "Doing" in the study of personality and cognition. American Psychologist, 45(6), 735-750.

Chase, W. G., \& Simon, H. A. (1973a). The mind's eye in chess. Visual information processing (pp. 215-281). Cambridge: Academic Press.

Chase, W. G., \& Simon, H. A. (1973b). Perception in chess. Cognitive Psychology, 4(1), 55-81.

Cohen, M. S., Kosslyn, S. M., Breiter, H. C., DiGirolamo, G. J., Thompson, W. L., Anderson, A. K., et al. (1996). Changes in cortical activity during mental rotation A mapping study using functional MRI. Brain, 119(1), 89-100.

Cushman, F. (2013). Action, outcome, and value: A dual-system framework for morality. Personality and Social Psychology Review, 17(3), 273-292.

Decety, J., Kawashima, R., Gulyas, B., \& Roland, P. E. (1992). Preparation for reaching: A PET study of the participating structures in the human brain. Neuroreport: An International Journal for the Rapid Communication of Research in Neuroscience, 3, 761-764.

Decety, J., \& Michel, F. (1989). Comparative analysis of actual and mental movement times in two graphic tasks. Brain and Cognition, 11(1), 87-97.

Driskell, J. E., Copper, C., \& Moran, A. (1994). Does mental practice enhance performance? Journal of Applied Psychology, 79(4), 481.

Duke, R. A., Simmons, A. L., \& Cash, C. D. (2009). It's not how much; it's how: Characteristics of practice behavior and retention of performance skills. Journal of Research in Music Education, 56(4), 310-321.

Endsley, M. (2006). Expertise and situation awareness. In K. Anders Ericsson (Ed.), The Cambridge handbook of expertise and expert performance (pp. 633-651). Cambridge: Cambridge University Press.

Ericsson, K. A., Krampe, R. T., \& Tesch-Römer, C. (1993). The role of deliberate practice in the acquisition of expert performance. Psychological Review, 100(3), 363.

Fantl, Jeremy, "Knowledge How", The Stanford Encyclopedia of Philosophy (Fall 2017 Edition), Edward N. Zalta (ed.), URL: https://plato.stanford.edu/archives/fall2017/entries/knowledge-how/.

Feltovich, P. J., Prietula, M. J., \& Ericsson, K. A. (2006). Studies of expertise from psychological perspectives. In K. Anders Ericsson (Ed.), The Cambridge handbook of expertise and expert performance (pp. 41-68). Cambridge: Cambridge University Press.

Feltz, D. L., \& Landers, D. M. (1983). The effects of mental practice on motor skill learning and performance: A metaanalysis. Journal of Sport Psychology, 5(1), 25-57.

Fridland, E. (2013a). Skill learning and conceptual thought: making a way through the wilderness. Contemporary philosophical naturalism and its implications (pp. 87-110). Abingdon: Routledge.

Fridland, E. (2013b). Imitation, skill learning, and conceptual thought: An embodied, developmental approach. Origins of mind (pp. 203-224). Dordrecht: Springer.

Fridland, E. (2014). They've lost control: Reflections on skill. Synthese, 191(12), 2729-2750.

Fridland, E. (2019). Longer, smaller, faster, stronger: On skills and intelligence. Philosophical Psychology, 32(5), 759-783.

Fridland, E., \& Moore, R. (2015). Imitation reconsidered. Philosophical Psychology, 28(6), 856-880.

Guillot, A., Nadrowska, E., \& Collet, C. (2009). Using motor imagery to learn tactical movements in Basketball. Journal of Sport Behavior, 32(2), 189-206. 
Hanakawa, T., Dimyan, M. A., \& Hallett, M. (2008). Motor planning, imagery, and execution in the distributed motor network: A time-course study with functional MRI. Cerebral Cortex, 18(12), 2775-2788.

Hanakawa, T., Immisch, I., Toma, K., Dimyan, M. A., Van Gelderen, P., \& Hallett, M. (2003). Functional properties of brain areas associated with motor execution and imagery. Journal of Neurophysiology, 89(2), 989-1002.

Heckhausen, J. (2007). The motivation-volition divide and its resolution in action-phase models of developmental regulation. Research in Human Development, 4(3-4), 163-180.

Hommel, B. (1993). Inverting the Simon effect by intention. Psychological Research, 55(4), 270-279.

Hommel, B. (2009). Action control according to TEC (theory of event coding). Psychological Research $P R P F, 73(4), 512-526$.

Hommel, B. (2015). The theory of event coding (TEC) as embodied-cognition framework. Frontiers in Psychology, 6, 1318.

Horn, J., \& Masunaga, H. (2006). A merging theory of expertise and intelligence. In K. Anders Ericsson (Ed.), The Cambridge handbook of expertise and expert performance (pp. 587-612). Cambridge: Cambridge University Press.

Hursthouse, R. (2016) Virtue Ethics. The Stanford Encyclopedia of Philosophy, Fall 2016 Edition, Edward N. Zalta (Ed.), URL = https://plato.stanford.edu/entries/ethics-virtue/.

Jacobson, D. (2005). Seeing by feeling. Ethical Theory and Moral Practice, 8, 387-409.

James, W., Burkhardt, F., Bowers, F., \& Skrupskelis, I. K. (1890). The principles of psychology (Vol. 1). London: Macmillan.

Jeannerod, M. (1994). The representing brain: Neural correlates of motor intention and imagery. Behavioral and Brain Sciences, 17(2), 187-202.

Kosslyn, S. M. (1999). If neuroimaging is the answer, what is the question? Philosophical Transactions of the Royal Society of London B: Biological Sciences, 354(1387), 1283-1294.

Kosslyn, S. M., Thompson, W. L., \& Ganis, G. (2006). The case for mental imagery. Oxford: Oxford University Press.

Krampe, R., \& Charness, N. (2006). Aging and expertise. In K. Ericsson Anders (Ed.), The Cambridge handbook of expertise and expert performance (pp. 723-742). Cambridge: Cambridge University Press.

Lapsley, D., \& Hill, P. (2008). On dual processing and heuristic approaches to moral cognition. Journal of Moral Education, 37(3), 313-332.

Madan, C. R., \& Singhal, A. (2012). Motor imagery and higher-level cognition: four hurdles before research can sprint forward. Cognitive Processing, 13(3), 211-229.

McDowell, J. (1998a). Virtue and reason. Mind, value \& reality (pp. 50-73). Cambridge: Harvard University Press.

McDowell, J. (1998b). Projection and truth in ethics. Mind, value \& reality (pp. 151-166). Cambridge: Harvard University Press.

Montero, B. (2016). Thought in action: Expertise and the conscious mind. Oxford: Oxford University Press.

Mylopoulos, M., \& Pacherie, E. (2017). Intentions and motor representations: The interface challenge. Review of Philosophy and Psychology, 8(2), 317-336.

Mylopoulos, M., \& Pacherie, E. (2018). Intentions: The dynamic hierarchical model revisited. Wiley Interdisciplinary Reviews: Cognitive Science, 10, e1481.

Prinz, W. (1997). Perception and action planning. European Journal of Cognitive Psychology, 9(2), $129-154$.

Rouse, W.B., \& Morris, N.M. (1985). On looking into the black box: Prospects and limits in the search for mental models (No. DTIC \#AD-A159080). Atlanta, GA: Center for Man-Machine Systems Research, Georgia Institute of Technology.

Schack, T. (2004). The cognitive architecture of complex movement. International Journal of Sport and Exercise Psychology, 2(4), 403-438.

Schack, T., Essig, K., Frank, C., \& Koester, D. (2014). Mental representation and motor imagery training. Frontiers in Human Neuroscience, 8, 328.

Schack, T., \& Mechsner, F. (2006). Representation of motor skills in human long-term memory. Neuroscience Letters, 391(3), 77-81.

Schmidt, R. A. (1975). A schema theory of discrete motor skill learning. Psychological Review, 82(4), 225.

Schmidt, R. A. (2003). Motor schema theory after 27 years: Reflections and implications for a new theory. Research Quarterly for Exercise and Sport, 74(4), 366-375. 
Seligman, M. E. P., Railton, P., Baumeister, R. F., \& Sripada, C. (2013). Navigating into the future or driven by the past. Perspectives on Psychological Science, 8(2), 119-141.

Sheldon, K. M., \& Elliot, A. J. (1999). Goal striving, need satisfaction, and longitudinal well-being: the self-concordance model. Journal of Personality and Social Psychology, 76(3), 482-497.

Sosa, E. (2007). A virtue epistemology: Apt belief and reflective knowledge (Vol. 1). Oxford: Oxford University Press.

Stanley, J., \& Krakauer, J. (2013). Motor skill depends on knowledge of facts. Frontiers of Human Neuroscience. https://doi.org/10.3389/fnhum.2013.0050.

Stichter, M. (2017). Virtue as Skill. In Nancy Snow (Ed.), Oxford handbook of virtue (pp. 57-84). New York: Oxford University Press.

Stichter, M. (2018). The skillfulness of virtue: Improving our moral and epistemic lives. Cambridge: Cambridge University Press.

Stichter, M. (2020). Virtue as a skill, self-regulation, and situationism. In F. Ellen \& P. Carlotta (Eds.), Routledge handbook of philosophy of skill and expertise. Abingdon: Routledge.

Sutton, R. S., \& Barto, A. G. (1998). Introduction to reinforcement learning (Vol. 2). Cambridge: MIT Press.

Sutton, J., McIlwain, D., Christensen, W., \& Geeves, A. (2011). Applying intelligence to the reflexes: Embodied skills and habits between Dreyfus and Descartes. Journal of the British Society for Phenomenology, 42(1), 78-103.

Zagzebski, L. (1996). Linda Zagzebski, Virtues of the Mind. Cambridge: Cambridge University Press.

Publisher's Note Springer Nature remains neutral with regard to jurisdictional claims in published maps and institutional affiliations. 